\title{
Nursing Diagnoses of hospitalized patients with heart failure: a longitudinal study
}

\author{
Diagnósticos de enfermagem em pacientes com insuficiência \\ cardíaca hospitalizados: estudo longitudinal \\ Diagnósticos de enfermería en pacientes con insuficiencia \\ cardiaca hospitalizados: estudio longitudinal
}

Juliana de Melo Vellozo Pereira ${ }^{1}$, Paula Vanessa Peclat Flores ${ }^{2}$, Lyvia da Silva Figueiredo ${ }^{1}$, Cristina Silva Arruda ${ }^{1}, K_{\text {Keila Mara }}$ Cassiano $^{3}$, Gláucia Cristina Andrade Vieira ${ }^{1}$, Thais de Rezende Bessa Guerra ${ }^{1}$, Vanessa Alves da Silva ${ }^{1}$, Ana Carla Dantas Cavalcanti ${ }^{1}$

How to cite this article:

Pereira JMV, Flores PVP, Figueiredo LS, Arruda CS, Cassiano KM, Vieira GCA, et al. Nursing Diagnoses of hospitalized patients with heart failure: a longitudinal study. Rev Esc Enferm USP. 2016;50(6):929-936. DOI: http://dx.doi.org/10.1590/S0080-623420160000700008

\footnotetext{
${ }^{1}$ Universidade Federal Fluminense, Programa de Pós-Graduação em Ciências Cardiovasculares, Niterói, RJ, Brazil.

${ }^{2}$ Universidade Federal Fluminense, Escola de Enfermagem Aurora de Afonso Costa, Departamento de Enfermagem Médico-Cirúrgica, Niterói, RJ, Brazil.

${ }^{3}$ Universidade Federal Fluminense, Instituto de Matemática, Departamento de Estatística, Niterói, RJ, Brazil.
}

\begin{abstract}
Objective: Identifying Nursing Diagnoses of fatigue, activity intolerance and decreased cardiac output in hospitalized patients with heart failure and verifying the association between the defining characteristics and the Nursing Diagnoses. Method: A longitudinal and prospective study that followed hospitalized patients with heart failure for three weeks. The data collected through interviews and physical examinations were sent to expert nurses for diagnostic inference. Descriptive and inferential statistical analyses were carried out. Results: Of the 72 patients, $68.0 \%$ were male and presented the nursing diagnosis of decreased cardiac output (62.5\%) in the first week, reducing to $52.8 \%$ and $38 \%$ in the second and third weeks, respectively. Fatigue only appeared in one patient. Activity intolerance was the diagnosis that had the greatest discrepancy among the experts. Decreased cardiac output was associated to the defining characteristics: dyspnea, edema, jugular venous distension and reduced ejection fraction during all three weeks of evaluation. Conclusion: Decreased cardiac output was more prevalent in hospitalized patients with heart failure, and the associated defining characteristics were determining factors for this nursing diagnosis.
\end{abstract}

\section{DESCRIPTORS}

Nursing Diagnoses; Heart Failure; Hospitalization; Nursing Process; Longitudinal Studies. 


\section{INTRODUCTION}

Heart failure (HF) is a clinical syndrome defined as the final pathway of cardiovascular diseases that cause inappropriate blood supply to organs and tissues ${ }^{(1-2)}$. Impaired ventricular ability to store or eject blood causes breathlessness and fatigue which limit exercise tolerance, as well as water retention leading to pulmonary congestion and peripheral edema. These clinical manifestations can impair the functional capacity and quality of life of patients with $\mathrm{HF}^{(3)}$.

HF has a chronic phase in which the patient is stable, and an acute decompensation phase marked by frequent hospital readmissions ${ }^{(1-2)}$. This phase is characterized by signs and symptoms of edema, dyspnea and fatigue related to the cardiac pump failure in maintaining sufficient flow to fulfill the body's needs ${ }^{(2)}$.

In taking care of hospitalized patients with $\mathrm{HF}$, nurses establish diagnoses for achieving outcomes through nursing interventions. NANDA International (NANDA-I) is a classification that standardizes Nursing Diagnoses (ND) offering titles, definitions, related factors and defining characteristics ${ }^{(4)}$.

In this classification, a combination of clinical descriptors from three NANDA-I nursing Diagnoses related to the cardiovascular function of hospitalized patients with $\mathrm{HF}$ can be noted, which are: fatigue, activity intolerance and decreased cardiac output. The latter two are shown in studies involving Nursing Diagnoses in patients with HF.

The nursing diagnosis of decreased cardiac output is defined by NANDA-I as "inadequate blood pumped by the heart to meet the metabolic demands of the body"(4). A Brazilian study that identified the priority Nursing Diagnoses in 303 patients with decompensated $\mathrm{HF}$ found a frequency of $100 \%$ for decreased cardiac output ${ }^{(5)}$. Another international study identified this diagnosis in $98 \%$ of hospitalized patients with $\mathrm{HF}$ and the activity intolerance diagnosis was found in $100 \%$ of the sample ${ }^{(6)}$. A review that identified Nursing Diagnoses in literature for hospitalized patients with HF showed that decreased cardiac output appeared in 58\% of the studies, while activity intolerance was found in $33.3 \%{ }^{(7)}$.

Activity intolerance is "insufficient physiological or psychological energy to endure or complete required or desired daily activities" ${ }^{(4)}$. It is considered a human response to $\mathrm{HF}$, representing fatigue symptoms and breathlessness to large, medium and small efforts reported by patients. It can restrict daily activities and quality of life.

$\mathrm{ND}$ of fatigue is "an overwhelming sustained sense of exhaustion and decreased capacity for physical and mental work at the usual level"(4). Despite this being a nursing diagnosis mainly cited in studies on patients with cancer, fatigue is a common complaint reported by patients with $\mathrm{HF}^{(8)}$. An international study with 200 patients with $\mathrm{HF}$ presented fatigue as one of the most common symptoms $(61.5 \%)^{(9)}$. Another study identified association of fatigue with reduced quality of life in patients with advanced HF in palliative care ${ }^{(10)}$.

The present study questions the presence of ND of fatigue, activity intolerance and decreased cardiac output in hospitalized patients with HF. These ND are determined by the defining characteristics found in the interviews and physical examinations, some of which are subjective or similar amongst each other, and which can interfere with the clinical judgment of nurses.

This study aimed to identify the Nursing Diagnoses of fatigue, activity intolerance and decreased cardiac output in hospitalized patients with heart failure and to verify the association between defining characteristics and the presence of these Nursing Diagnoses.

This study can be justified for providing nurses with evidence on the presence and/or absence of the Nursing Diagnoses of fatigue, activity intolerance and decreased cardiac output in hospitalized patients with HF, facilitating judgment and decision-making in professional practice.

\section{METHOD}

\section{DESIGN}

An observational, longitudinal and prospective study conducted with hospitalized patients with heart failure in two centers located in Niterói, RJ, Brazil.

\section{Study POPULATION AND SAMPLE}

The population consisted of hospitalized patients with heart failure over a period of 12 months (171 patients between 2011 and 2012), considering a simple random sampling selection and overall margin of error resulting in a maximum of $\mathrm{n}$ $=5 \%$. Total sample size corrected by the size of the $\mathrm{N}$ population was calculated using the following formula: $n=\left(z^{2} p q /\right.$ $\left.\mathrm{d}^{2}\right) / 1+\left(\mathrm{z}^{2} \mathrm{pq} / \mathrm{Nd}^{2}\right)^{(11)}$. The sample selected for this study respecting the inclusion and exclusion criteria included 70 patients. Therefore, the estimated ratios in this study are subject to maximum error of $8.75 \%$ and a $95 \%$ confidence level.

The sample selection was non-probabilistic with an initial composition of 84 patients, but with four losses due to hospital discharge before the end of data collection, six losses due to death and two losses due to discontinuity by transfers. The final sample consisted of 72 patients followed for three weeks of hospitalization from the time of hospital admission.

Inclusion criteria were: being over 18 years of age; medical diagnosis of heart failure according to the Boston and Framingham criteria, agreeing to participate and signing the Clear and Informed Consent Form ${ }^{(1)}$. Losses due to medical discharge, patient death and transfers in the period of data collection were considered as exclusion criteria.

\section{Data Collection}

Data collection was based on a previously developed and evaluated instrument by experts in the area. It was designed with closed and open questions according to the NANDA-I domains representing spheres of activity ${ }^{(6)}$. It consists of patient characterization information (age, gender, income per capita, years of education, self-declared racial type, disease duration, treatment time, previous history of disease, family history of disease and city of origin), a review of symptoms and systems, quality of life assessed by the Minnesota Living With Heart Failure Questionnaire (version validated in Brazil), laboratory tests (complete blood count, sodium, potassium, urea, creatinine, glucose and coagula- 
tion), echocardiogram report, chest radiography and medications used during hospitalization, in addition to the evaluation of cardiac diagnoses ${ }^{(12)}$

NANDA-I has 37 defining characteristics for the nursing diagnosis of decreased cardiac output, classified according to the following subclasses: behavioral/emotional, altered contractility, altered heart rate/rhythm, altered afterload and altered preload ${ }^{(4)}$. Activity intolerance has eight defining characteristics and the fatigue diagnosis has $19^{(4)}$. Operational definitions of the defining characteristics for fatigue, activity intolerance and decreased cardiac output were included in the data collection instrument so that they would later be analyzed in the diagnostic inference process by experts involved in this study. These operational definitions were extracted from studies that performed the clinical and content validation of their diagnoses ${ }^{(13-15)}$.

A pilot test with $10 \%$ of the patients was conducted in order to verify the adequacy of the instrument to the study objectives, as well as the capability and difficulties of applying it in the practical field by the researcher. After this test, the instrument was considered adequate and patients who participated were included in the total study sample.

Data collection was performed by the researcher and two properly trained nurses between April 2011 and March 2012, being divided into three stages. First, the medical records were consulted to identify whether the patient met the inclusion criteria. Once the patient was selected, laboratory and radiological tests, and evolutions and prescriptions from all professionals involved in the treatment process were collected.

Subsequently, the researchers were introduced to the patient and applied the data collection instrument through interviews and physical examination. Patients had their data collected by the same people for three weeks. They were followed for three weeks of hospitalization from the period of admission, and were evaluated every seven days.

\section{Diagnostic InfeRENCE}

This stage of the study involved participation of nurses from the Nursing Care Systematization Group of the Universidade Federal Fluminense (UFF-GESAE), registered in the $\mathrm{CNPq}$ directory. We emphasize that the nurses who collected the patients' data did not participate in this stage.

The criteria for nurses' participation in this study were: having graduated in nursing, having research/studies published in the areas of Nursing and Heart failure, and having taught or having clinical practice for at least 1 year.

Nurses had their Lattes curriculum evaluated according to the above criteria. Six nurses were selected who then signed a Clear and Informed Consent Form after accepting to participate in the study.

In order to reduce possible bias on diagnostic inference, nurses were trained to participate in the study ${ }^{(16)}$. Later, they received data collection instruments and a chart with the operational definitions of the defining characteristics of the studied diagnoses, which would independently determine the presence or absence of the Nursing Diagnoses and the defining characteristics of the 72 patients collected at three times (216 clinical cases in total).
Presence or absence of diagnoses was considered when there was agreement from four expert nurses. We emphasize that this study does not aim to validate the content of the Nursing Diagnoses in question, but rather evaluate their presence or absence in patients with $\mathrm{HF}$.

According to the literature, it is known that a rate equal or greater than 0.78 should be considered acceptable ${ }^{(17)}$ for the correlation calculation and the percentage content validity index (CVI) in the case of six or more experts. Still, although the present study did not address a diagnostic validation, we chose to use an approximate value from the literature (0.67, equivalent to four experts) as a minimum acceptable rate, considering that this could represent what most experts agree on for diagnostic inferences, since it deals with verifying Nursing Diagnoses that have similar characteristics to one another.

\section{Data ANALYSIS}

Data from the research instrument were entered into a home computer and stored in the database using Microsoft Excel 2013 and SPSS version 20.0 for statistical analysis.

Descriptive analysis presented frequency distributions, calculation of statistics, mean and standard deviation for the variables age, per capita income, years of education, disease duration and HF treatment, quality of life score and ejection fraction of the left ventricle, which were transversally evaluated.

Chi-square test and Fisher's exact test were used to evaluate the association between defining characteristics and the Nursing Diagnoses. The McNemar test was used to identify the evolution of the Nursing Diagnoses and defining characteristics. Differences were considered statistically significant for all cases when the $\mathrm{p}$-value associated with the analysis was lower than 0.05 .

\section{ETHICAL ASPECTS}

This study was approved by the Research Ethics Committee of the School of Medicine of the Universidade Federal Fluminense under Opinion No. 011/2010, and required signing of the Clear and Informed Consent Form by patients for participating in the research.

\section{RESULTS}

Table 1 shows the clinical and sociodemographic variables of the patients in the study. There was a predominance of males $(68 \%)$ with a mean age of $54.5 \pm 13$ years, per capita income with a median of $\mathrm{R} \$ 545,00$ (BRL) and an education level around 6 years. Most are economically inactive (69.4\%). $\mathrm{HF}$ duration and treatment is 24 months.

Patients were hospitalized with functional class III (52.2\%), ischemic etiology (75.0\%) and reduced ejection fraction. Hypertension and acute myocardial infarction were the most present (69.4\%) comorbidities. A high prevalence of poor adherence to water-salt restriction was observed as a cause of decompensated $\mathrm{HF}$, and $38.9 \%$ of patients were previously hospitalized or admitted to emergency units in the last 3 months prior to the study. 
Table 1 - Clinical and sociodemographic variables of hospitalized patients with heart failure - Niterói, RJ, Brazil, 2012.

\begin{tabular}{|c|c|c|}
\hline Clinical and sociodemographic variables & $n(\%)$ & Mean \pm SD \\
\hline Gender, male & $49.0(68 \%)$ & - \\
\hline Age (years), mean $\pm S D$ & - & $54.5 \pm 13$ \\
\hline Income per capita $\mathrm{R} \$ 545,00(\mathrm{BRL})^{*}$ & - & $545.0(272.2-806.2)^{*}$ \\
\hline Education level (years)* & - & $60.0(5.0-9.0)^{*}$ \\
\hline Disease duration (months)* & - & $24.0(7-96)^{*}$ \\
\hline Self-declared racial type, Pardo & $42.0(58.3 \%)$ & - \\
\hline Source of income, Inactive & $50.0(69.4 \%)$ & - \\
\hline Functional classification (NYHA), III & $37.6(52.2 \%)$ & - \\
\hline Etiology, ischemic & $54.0(75.0 \%)$ & - \\
\hline Left ventricular ejection fraction $(\%)^{*}$ & $33.0(23.0-46.0)$ & - \\
\hline Comorbidities & & - \\
\hline Arterial hypertension & $50.0(69.4 \%)$ & - \\
\hline Acute myocardial infarction & $50.0(69.4 \%)$ & - \\
\hline Alcohol consumption & $62.9(87.4 \%)$ & - \\
\hline Smoking & $50.0(69.4 \%)$ & - \\
\hline Reason for decompensation, poor adherence to water-salt restriction & $62.0(86.1 \%)$ & - \\
\hline Readmission/emergency admission in the last three months & $28.0(38.9 \%)$ & - \\
\hline
\end{tabular}

*Variables expressed as median and interquartile range.

Note: $(\mathrm{n}=72)$.

Table 2 shows the frequency of ND studied regarding the presence, absence and discrepancies among the experts. Regarding the diagnosis of decreased cardiac output in the first week, it had a prevalence of $62.5 \%$, in the second week it reduced to $52.8 \%(\mathrm{n}=38)$, and in the third week it was present in 28 patients (38.9\%).
Fatigue only appeared in one patient over the three weeks, with the presence of the defining characteristic "tiredness". ND activity intolerance showed the greatest discrepancy among the experts (51.4\%; 43.1\%; 40.3\%, respectively). The defining characteristic "dyspnea on exertion" was identified in three patients in the first and third weeks, and in two patients in the second week.

Table 2 - Frequency of the Nursing Diagnoses of fatigue, activity intolerance and decreased cardiac output identified in hospitalized in patients with HF after concordance analysis by the expert nurses - Niterói, RJ, Brazil, 2012.

\begin{tabular}{|c|c|c|c|}
\hline Nursing Diagnoses & Present $(\%)$ & Absent (\%) & Discrepancies (\%) \\
\hline \multicolumn{4}{|c|}{ Decreased cardiac output } \\
\hline Week 1 & $45(62.5)$ & $11(15.3)$ & $16(22.2)$ \\
\hline Week 2 & $38(52.8)$ & $16(22.2)$ & $18(25.0)$ \\
\hline Week 3 & $28(38.9)$ & $19(26.4)$ & $24(33.3)$ \\
\hline \multicolumn{4}{|l|}{ Activity intolerance } \\
\hline Week 1 & $3(4.2)$ & $32(44.4)$ & $37(51.4)$ \\
\hline Week 2 & $2(2.8)$ & $39(54.2)$ & $31(43.1)$ \\
\hline Week 3 & $3(4.2)$ & $40(55.6)$ & $29(40.3)$ \\
\hline \multicolumn{4}{|l|}{ Fatigue } \\
\hline Week 1 & $1(1.4)$ & $62(86.1)$ & $10(13.9)$ \\
\hline Week 2 & $1(1.4)$ & $66(91.7)$ & $5(6.9)$ \\
\hline Week 3 & $1(1.4)$ & $66(91.7)$ & $5(6.9)$ \\
\hline
\end{tabular}

Note: $(\mathrm{n}=72)$.

Table 3 shows the frequency of the ND decreased cardiac output and the most common defining characteristics present in the course of three weeks. This ND and the characteristics "edema", "jugular venous distension" and "dyspnea" by the McNemar test showed a statistically significant reduction in frequency between the first and last week of evaluation.
Chart 1 depicts the significant results of the Chi-square and Fisher's exact test between decreased cardiac output and its defining characteristics. This ND was statistically associated to four defining characteristics in the three weeks of evaluation (dyspnoea, jugular venous distension, edema and reduced ejection fraction). 
Table 3 - Frequency of the decreased cardiac output nursing diagnosis and defining characteristics in hospitalized patients with heart failure - Niterói, RJ, Brazil, 2012.

\begin{tabular}{|c|c|c|c|c|}
\hline Decreased cardiac output & $\begin{array}{c}\text { Week } 1 \\
(\%)\end{array}$ & $\begin{array}{c}\text { Week } 2 \\
(\%)\end{array}$ & $\begin{array}{c}\text { Week } 3 \\
(\%)\end{array}$ & $p$-value \\
\hline & $45.0(62.5)$ & $38.0(52.8)$ & $28.0(22.2)$ & 0.013 \\
\hline \multicolumn{5}{|l|}{ Defining characteristics } \\
\hline Edema & $25.0(40.3 \%)$ & $20.0(32.3 \%)$ & $15.0(24.2 \%)$ & 0.004 \\
\hline Jugular venous distension & $23.0(37.1 \%)$ & $17.0(27.4 \%)$ & $13.0(21.0 \%)$ & $\mathrm{p}<0.001$ \\
\hline Dyspnoea & $22.0(35.5 \%)$ & $16.0(25.8 \%)$ & $9.0(14.5 \%)$ & 0.02 \\
\hline Changes in skin color & $12.0(19.3 \%)$ & $10.0(16.1 \%)$ & $10.0(16.1 \%)$ & NS* \\
\hline Fatigue & $10.0(16.1 \%)$ & $5.0(8.1 \%)$ & $4.0(6.4 \%)$ & NS* \\
\hline
\end{tabular}

*NS: not significant.

Note: $(n=62)$.

Chart 1 - Presentation of the $p$ values resulting from the chi-square test between the nursing diagnosis of decreased cardiac output and defining characteristics - Niterói, RJ, Brazil, 2012.

\begin{tabular}{|c|c|c|c|}
\hline Variables & $\begin{array}{l}p \text {-value } \\
\text { Week } 1\end{array}$ & $\begin{array}{l}p \text {-value } \\
\text { Week } 2\end{array}$ & $\begin{array}{l}p \text {-value } \\
\text { Week } 3\end{array}$ \\
\hline \multicolumn{4}{|c|}{ Decreased cardiac output } \\
\hline \multicolumn{4}{|l|}{ Defining characteristics } \\
\hline Dyspnoea & 0.001 & 0.001 & 0.003 \\
\hline Jugular venous distension & 0.002 & 0.001 & 0.001 \\
\hline Edema & 0.00 & 0.00 & 0.0001 \\
\hline Arrhythmias & NS & $0.038^{* *}$ & NS \\
\hline Changes of skin color & NS & $0.013^{* *}$ & $0.004 * *$ \\
\hline B3 sounds & NS & NS & $0.002^{* *}$ \\
\hline Reduced ejection fraction & 0.025 & 0.001 & $0.022^{* *}$ \\
\hline
\end{tabular}

*NS: not significant; **Fisher exact test.

\section{DISCUSSION}

This study found for the first time that decreased cardiac output is the most frequent diagnosis in patients in the three weeks of hospital follow-up (62.5\%, 52.8\%, 22.2\%, respectively). It should be noted that a low frequency of identifying the ND of activity intolerance was found and there was a high prevalence of discrepancies among the experts in evaluating this diagnosis. Fatigue was only prevalent in one hospitalized patient with HF during hospitalization.

The nursing diagnosis of decreased cardiac output has been clinically validated in 29 patients admitted for decompensated HF, where fatigue $(r=1)$, dyspnea $(r=0.96)$, edema $(\mathrm{r}=0.95)$, orthopnea $(\mathrm{r}=0.88)$ and elevated central venous pressure $(\mathrm{r}=0.85)$ were considered the most important defining characteristics ${ }^{(14)}$. Another study conducted in the USA with 302 patients showed that $77.1 \%$ had this ND. A survey of 77 electronic records of hospitalized patients with cardiovascular disease showed that cardiac output was considered a priority for the studied sample ${ }^{(5,18)}$.

In the present study, there was a reduction in frequency over time of the ND decreased cardiac output and its most common characteristics (edema, jugular vein distention and dyspnea). This finding may reflect a positive response of patients to therapeutic interventions and its monitoring during hospitalization allows for observing the care impact provided to the patient.

Decreased cardiac output was found to be associated to the defining characteristics of dyspnoea, jugular venous distension, edema and reduced ejection fraction in the three weeks of evaluation, representing the responses of hospitalized patients with HF in this study.

Regarding the characteristics dyspnea and edema, a Brazilian study with 303 hospitalized patients with decompensated HF identified the following main defining characteristics: dyspnea, orthopnea, paroxysmal nocturnal dyspnea, exhaustion, edema, jugular venous distension and reduced ejection fraction, corroborating the results of this study ${ }^{(6)}$. A systematic review that characterized publications related to the nursing diagnosis of decreased cardiac output found 11 defining characteristics were most cited in the evaluated articles, among them dyspnea (76.9\%) and edema $(61.1 \%)^{(19)}$.

Jugular venous pressure/turgescence is a finding that represents better diagnostic performance ${ }^{(3)}$. The most frequently observed clinical manifestations are generally congestive, with a percentage of $80.7 \%$ in patients admitted to emergency rooms ${ }^{(4)}$. 
Regarding the defining characteristic reduced ejection fraction, this was an important finding in a retrospective study that aimed to identify prevalence of the defining characteristics of decreased cardiac output in 38 patients with HF being evaluated for heart transplantation, and to verify the chance of these defining characteristics being predictive factors for the occurrence of ND in the study. Increased systemic vascular resistance $(\mathrm{OR}=4.533)$, third heart sound $(\mathrm{OR}=3.429)$ and decreased ejection fraction $(\mathrm{OR}=2.850)$ were evidenced ${ }^{(20)}$.

The ND of activity intolerance was found in low prevalence in the patients. However, the high percentage of disagreement among experts in the weekly ratings is highlighted (51.4\%, $43.1 \%$ and $40.3 \%$, respectively). It is possible to justify this discrepancy due to the fact that identifying the presence of activity intolerance depends on verifying the patient in bed, if at rest, if they can walk and how, the height of head elevation and how this symptom is described by the patient at the time of the interview. Since patients are decompensated, ergonomic tests to quantify the degree of activity intolerance cannot be carried out; therefore the evaluation is subjective, which may limit the diagnostic inference.

The defining characteristic of dyspnea upon exertion, being the only one found in this study for this diagnosis, could be inserted into the defining characteristic dyspnoea, belonging to the nursing diagnosis of decreased cardiac output. Thus, it is possible that the experts considered it as activity intolerance in the therapeutic context of hospitalized patients with HF, being inserted in the ND context of decreased cardiac output, in which dyspnea was one of the more present defining characteristics.

Activity intolerance was clinically validated in 22 hospitalized patients with angina, with verbal report characteristics of fatigue $(r=0.95)$, electrocardiographic changes reflecting ischemia $(r=0.89)$ and abnormal heart rate response to activity $(r=0.85)$ being considered to be the most relevant ${ }^{(21)}$. A prevalence study that evaluated the defining characteristics of the ND activity intolerance, decreased cardiac output and excessive volume of fluid in 25 patients with decompensated $\mathrm{HF}$ showed that $100 \%$ of patients were diagnosed with decreased cardiac output and $96 \%$ had activity intolerance ${ }^{(22)}$. Another study which described the use of nursing terminologies in care plans made for 76 patients in a cardiac rehabilitation unit showed $100 \%$ of patients with activity intolerance and decreased cardiac output ${ }^{(23)}$.

Despite the aforementioned studies having identified activity intolerance with high prevalence, it is important to identify the method used and the profile of the analyzed patients. In this study, as already described, most of the patients presented functional class III and IV. These functional classes represent severe $\mathrm{HF}$ and with high risk of readmissions and mortality due to hemodynamic instability, and decreased cardiac output could be a better response mode of patients to the disease, treatment and hospitalization than activity intolerance.

ND fatigue was identified in only one patient in the weekly evaluations with few disagreements among the experts $(13.9 \%, 6.9 \%$ and $6.9 \%$, respectively). It is noteworthy that fatigue according to NANDA-I is also described as a defining characteristic of the ND decreased cardiac output, activity intolerance and seven other NDs belonging to other domains and classes ${ }^{(4)}$.

Fatigue is considered a phenomenon of physical, cognitive, and emotional causes, and it reduces the quality of life ${ }^{(24)}$. Tiredness, feeling exhausted, decreased functional capacity and difficulty to obtain energy are inherent characteristics of fatigue ${ }^{(25)}$. However, the attempt to include causes or related factors to try to meet everything that fatigue means can bring forth difficulties in evaluating it.

Fatigue is one of the most prevalent complaints in patients with $\mathrm{HF}$ and it has already been associated to dyspnea, a decline in physical and emotional health, depression, insomnia, reduced ejection fraction and worsening of functional class, being more present in women and betablockers users ${ }^{(25)}$.

Thus, we question whether the definition of the symptom "fatigue" presented in the studies is the same definition for nursing diagnosis, and if the defining characteristics are enough for the symptoms in hospitalized patients with HF. Patients who reported feeling fatigue can translate several symptoms at the same time, including dyspnea and exhaustion, which are closely related. This possibility is also justified since fatigue is a multidimensional phenomenon ${ }^{(26)}$.

In addition, in considering that decreased cardiac output could integrate the responses of patients to hospitalization and HF, the experts stated that this is a priority diagnosis with respect to nursing interventions and outcomes. Thus, treating the patient, planning care and nursing staff workload would be optimized.

As limitations of this study, we can mention that ergometric tests were not performed for a better evaluation of Nursing Diagnoses, and also the high prevalence occurrence of discrepancies between experts, especially regarding the ND of activity intolerance.

We suggest that further studies are conducted using larger samples and multiple scenarios to confirm the nursing diagnosis of decreased cardiac output as an indicator of the quality of nursing care in patients hospitalized with HF.

\section{CONCLUSION}

The nursing diagnosis of decreased cardiac output was the most prevalent along the three weeks of study evaluation. The defining characteristics of dyspnea, edema, jugular venous distension and reduced ejection fraction were associated with this diagnosis. The high prevalence of the decreased cardiac output diagnosis and its more present defining characteristics being monitored during hospitalization may become quality of nursing care indicators in HF in hospitals.

Nurses who care for patients with HF deal with a variety of signs and symptoms during hospitalization that can confuse the diagnostic accuracy, and therefore the planning of individualized and targeted interventions. In this sense, the activity intolerance diagnosis needs to be better elucidated in literature due to the high prevalence of discrepancies between experts. 
RESUMO

Objetivo: Identificar os diagnósticos de enfermagem fadiga, intolerância à atividade e débito cardíaco diminuído em pacientes com insuficiência cardíaca hospitalizados e verificar a associação entre as características definidoras e os diagnósticos de enfermagem. Método: Estudo longitudinal e prospectivo que acompanhou pacientes com insuficiência cardíaca hospitalizados por três semanas. Os dados coletados por entrevista e exame físico foram encaminhados a enfermeiros peritos para inferência diagnóstica. Realizou-se análise estatística descritiva e inferencial. Resultados: Dos 72 pacientes, 68,0\% eram do sexo masculino e apresentaram o diagnóstico de enfermagem débito cardíaco diminuído (62,5\%) na primeira semana, reduzindo para 52,8\% e 38\% na segunda e terceira semana, respectivamente. Fadiga apareceu somente em um paciente. Intolerância à atividade foi o diagnóstico que teve maior discordância entre os peritos. Débito cardíaco diminuído foi associado às características definidoras dispneia, edema, distensão da veia jugular e fração de ejeção diminuída nas três semanas de avaliação. Conclusão: Débito cardíaco diminuído esteve mais prevalente em pacientes com insuficiência cardíaca hospitalizados, sendo as características definidoras associadas determinantes para este diagnóstico de enfermagem.

\section{DESCRITORES}

Diagnóstico de Enfermagem; Insuficiência Cardíaca; Hospitalização; Processos de Enfermagem; Estudos Longitudinais.

\section{RESUMEN}

Objetivo: Identificar los diagnósticos de enfermería: fatiga, intolerancia a la actividad y débito cardíaco diminuido en pacientes con insuficiencia cardiaca hospitalizados y verificar la asociación entre las características definidoras y los diagnósticos de enfermería. Método: Estudio longitudinal y prospectivo que acompañó a pacientes con insuficiencia cardiaca hospitalizados por tres semanas. Los datos recogidos por entrevista y examen físico fueron remitidos a enfermeros expertos para inferencia diagnóstica. Se llevó a cabo el análisis estadístico descriptivo e inferencial. Resultados: De los 72 pacientes, el 68,0\% eran del sexo masculino y presentaron el diagnóstico de enfermería débito cardiaco disminuido (62,5\%) en la primera semana, reduciendo al $52,8 \%$ y al $38 \%$ en la segunda y tercera semana, respectivamente. La fatiga apareció solo en un paciente. Intolerancia a la actividad fue el diagnóstico que tuvo mayor discordancia entre los expertos. Débito cardiaco disminuido estuvo asociado con las características definidoras dispneia, edema, distensión de la vena yugular y fracción de eyección disminuida en las tres semanas de evaluación. Conclusión: Débito cardiaco disminuido estuvo más prevalente en pacientes con insuficiencia cardiaca hospitalizados, siendo las características definidoras determinantes para dicho diagnóstico de enfermería.

\section{DESCRIPTORES}

Diagnóstico de Enfermería; Insuficiência Cardíaca; Hospitalización; Procesos de Enfermería; Estudios Longitudinales.

\section{REFERENCES}

1. Bocchi EA, Marcondes FG, Bacal F, Ferraz AS, Albuquerque D, Rodrigues D, et al.; Sociedade Brasileira de Cardiologia. Atualização da diretriz brasileira de insuficiência cardíaca crônica - 2012. Arq Bras Cardiol [Internet]. 2012 [citado 2016 fev. 28]; 98(1 Supl.1):1-33. Disponível em: from: http://publicacoes.cardiol.br/consenso/2012/Diretriz\%20IC\%20Cr\%C3\%B4nica.pdf

2. Albuquerque DC, Souza Neto JD, Bacal F, Rohde LE, Bernardez-Pereira S, Berwanger O, et al. I Registro Brasileiro de Insuficiência Cardíaca: aspectos clínicos, qualidade assistencial e desfechos hospitalares. Arq Bras Cardiol [Internet]. 2015 [cited 2016 Jan 17];104(6):433-42. Available from: http://www.scielo.br/pdf/abc/v104n6/pt_0066-782X-abc-20150031.pdf

3. Yancy CW, Jessup M, Chair V, Bozkurt B, Butler J, Casey D, et al. 2013 ACCF/AHA guideline for the management of heart failure: a report of the American College of Cardiology Foundation/American Heart Association Task Force on practice guidelines. Circulation. 2013;128(16):e240-327.

4. Herdman TH, Kamitsuru SE. Nanda International. Nursing Diagnoses 2015-17: Definitions and Classification. Oxford: Wiley Blackwell; 2014.

5. Scherb CA, Head BJ, Maas ML, Swanson EA, Moorhead S, Reed D, et al. Most frequent nursing diagnoses, nursing interventions, and nursing-sensitive patient outcomes of hospitalized older adults with heart failure: part 1. Int J Nurs Terminol Classif. 2011;22(1):13-22.

6. Aliti GB, Linhares JCC, Linch GFC, Ruschel KB, Rabelo ER. Sinais e sintomas de pacientes com insuficiência cardíaca descompensada: inferência dos diagnósticos de enfermagem prioritários. Rev Gaúcha Enferm [Internet]. 2011 [citado 2016 jan. 20]; 32(3):590-5. Available from: http://www.scielo.br/pdf/rgenf/v32n3/22.pdf

7. Cavalcanti ACD, Pereira JMV. Nursing diagnoses of patients with heart failure: an integrative review. Online Braz J Nurs [Internet]. 2014 [cited 2016 Jan 20];13(1):113-25. Available from: http://www.objnursing.uff.br/index.php/nursing/article/viewFile/3916/pdf_107

8. Schjoedt I, Sommer I, Bjerrum MB. Experiences and management of fatigue in everyday life among adult patients living with heart failure: a systematic review of qualitative evidence. JBI Database System Rev Implement Rep. 2016;14(3):68-115.

9. Rojas Sánchez LZ, Hernández Vargas JA, Trujillo Cáceres SJ, Roa Díaz ZM, Jurado Arenales AM, Toloza Pérez YG. Usefulness of the diagnosis "Decreased Cardiac Output (00029)" in patients with chronic heart failure. Int J Nurs Knowl. 2016 May 31. [Epub ahead of print].

10. Yu DS, Chan HY, Leung DY, Hui E, Sit JW. Symptom clusters and quality of life among patients with advanced heart failure. J Geriatr Cardiol. 2016;13(5):408-14.

11. Callegari-Jacques SSM. Bioestatística: princípios e aplicações. Porto Alegre: Artmed; 2003.

12. Carvalho CV, Guimarães GV, Carrara D, Bacal F, Bocchi EA. Validation of the Portuguese Version of the Minnesota Living with Heart Failure Questionnaire. Arq Bras Cardiol. 2009;93(1):39-44.

13. Rodrigues CG, Moraes MA, Sauer JM, Kalil RAK, Souza EN. Nursing diagnosis of activity intolerance: clinical validation in patients with refractory angina. Int J Nurs Terminol Classif. 2011;22(3):117-22.

14. Martins QCS, Aliti G, Rabelo ER. Decreased cardiac output: clinical validation in patients with decompensated heart failure. Int J Nurs Terminol Classif. 2010;21(4):156-65. 
15. Silva PO, Gorini MIPC. Validation of defining characteristics for the nursing diagnosis of fatigue in oncological patients. Rev Latino Am Enfermagem. 2012;20 (3):504-10.

16. Pereira JMV, Cavalcanti ACD, Lopes MVO, Silva VG, Souza RO, Gonçalves LC, et al. The accuracy in inference of nursing diagnosis in heart failure inpatients. Rev Bras Enferm [Internet]. 2015 [cited 2016 Jan 15];68(3):603-9. Available from: http://www.scielo.br/pdf/reben/ v68n4/en_0034-7167-reben-68-04-0690.pdf

17. Costa ANM, Orpinelli CMZ. Validade de conteúdo nos processos de construção e adaptação de instrumentos de medidas. Ciênc Saúde Coletiva [Internet]. 2011;16(7): 3061-8.

18. Costa C, Costa Linch GF, Souza EN. Nursing diagnosis based on signs and symptoms of patients with heart disease. Int J Nurs Knowl. 2016 Mar 16. [Epub ahead of print].

19. Souza V, Zeitoun SS, Barros ABL. Débito cardíaco diminuído: revisão sistemática das características definidoras. Acta Paul Enferm [Internet]. 2011 [citado 2016 mar. 29]; 24(1):114-9. Available from: http://www.scielo.br/pdf/ape/v24n1/v24n1a17.pdf

20. Matos LN, Guimarães TCF, Brandão MAG, Santoro DC. Prevalence of nursing diagnosis of decreased cardiac output and the predictive value of defining characteristics in patients under evaluation for heart transplant. Rev Latino Am Enfermagem [Internet]. 2012 [cited 2016 Mar 29];20(2):307-15. Available from: http://www.scielo.br/pdf/rlae/v20n2/13.pdf

21. Rodrigues CG, Moraes MA, Sauer JM, Kalil RA, Souza EN. Nursing diagnosis of activity intolerance: clinical validation in patients with refractory angina. Int J Nurs Terminol Classif. 2011;22(3):117-22.

22. Souza V, Zeitoun SS, Lopes CT, Oliveira AP, Lopes JL, Barros AL. Clinical usefulness of the definitions for defining characteristics of activity intolerance, excess fluid volume and decreased cardiac output in decompensated heart failure: a descriptive exploratory study. J Clin Nurs. 2015;24(17-18):2478-87.

23. Zampieron A, Silla A, Corso M. A retrospective study of nursing diagnoses, outcomes and interventions for patients admitted to a cardiology rehabilitation unit. Int J Nurs Terminol Classif. 2011;22(4):148-56.

24. Williams YJ, Jantke RL, Jason LA. Chronic fatigue syndrome: case definitions, possible causes, and therapies. Altern Complement Ther. 2015;21(5):217-23.

25. Fink AM, Gonzalez RC, Lisowski T, Pini M, Fantuzzi G, Levy WC, et al. Fatigue, inflammation and projected mortality in heart failure. J Card Fail. 2012;18(9):711-6.

26. Luyten P, Kempke S, Van Wambeke P, Claes S, Blatt SJ, Van Houdenhove B. Self-critical perfectionism, stress generation, and stress sensitivity in patients with chronic fatigue syndrome: relationship with severity of depression. Psychiatry. 2011; 74(1):21-30. 